\title{
A Comparative Study of Addition of Midazolam to Lignocaine-Bupivacaine vs only Lignocaine- Bupivacaine in Brachial Plexus Block
}

\author{
${ }^{1}$ Naina P Dalvi, ${ }^{2}$ Harshali Salunkhay, ${ }^{3}$ Shubha N Mohite
}

\begin{abstract}
Introduction: This prospective, randomized, double-blind study compared the onset and duration of sensory blockade, motor blockade, and analgesia with lignocaine, bupivacaine, and midazolam combination vs only lignocaine, bupivacaine in brachial plexus block.
\end{abstract}

Materials and methods: Patients of either sex, aged 18-60 years, American Society of Anesthesiologists grade I/II, posted for upper limb surgeries to be performed under supraclavicular brachial plexus block with the help of peripheral nerve stimulator were administered either $10 \mathrm{ml} 0.5 \%$ bupivacaine with $50 \mu \mathrm{g} / \mathrm{kg}$ midazolam (preservative free) $+20 \mathrm{ml} 2 \%$ lignocaine with adrenaline $(1: 200,000)$ in Group lignocainebupivacaine-midazolam (LBM) or $10 \mathrm{ml} 0.5 \%$ bupivacaine + $20 \mathrm{ml} \mathrm{2 \%}$ lignocaine with adrenaline $(1: 200,000)$ in Group lignocaine-bupivacaine (LB).

Onset and duration of sensory and motor blockade were monitored. Postoperative analgesia was graded with visual analog scale. Sedation was monitored with Ramsey sedation score.

Results: A total of 60 patients were randomized to the group LBM $(n=30)$ and group LB $(n=30)$. The analgesia was significantly prolonged in the study group, with a mean of $11.72 \pm 1.924$ hours as compared with a mean of $6.383 \pm 1.031$ hours in the control group. Sedation scores were higher in the study group, that is, group LBM compared to group LB postoperatively.

Conclusion: In conclusion, midazolam when added to bupivacaine and adrenalized lignocaine for supraclavicular brachial plexus block hastens the onset of sensory and motor blockade. This combination improves analgesia, as manifested by lower pain scores and prolonged duration of analgesia.

Keywords: Brachial plexus block, Midazolam in local anesthetics, Postoperative analgesia.

How to cite this article: Dalvi NP, Salunkhay H, Mohite SN. A Comparative Study of Addition of Midazolam to LignocaineBupivacaine vs only Lignocaine-Bupivacaine in Brachial Plexus Block. Res Inno in Anaesth 2016;1(1):5-9.

Source of support: Nil

Conflict of interest: None

\footnotetext{
${ }^{1}$ Additional Professor, ${ }^{2}$ Ex-Resident, ${ }^{3}$ Ex-Professor and Head ${ }^{1}$ Department of Anaesthesia, HBTMC and Dr RN Cooper Hospital, Mumbai, Maharashtra, India

${ }^{2,3}$ Department of Anaesthesia, LTMMC and LTMG Hospital Mumbai, Maharashtra, India

Corresponding Author: Naina P Dalvi, Additional Professor Department of Anaesthesia, HBTMC and Dr RN Cooper Hospital Vileparle, Mumbai, Maharashtra, India, Phone: +919820711656 e-mail: drnaina@rediffmail.com
}

\section{INTRODUCTION}

Any expertise in anesthesia requires knowledge of pain relief during surgery and also into the postoperative period. The aim of postoperative pain relief is to provide comfort and to inhibit trauma-induced nociceptive impulses, thereby blunting autonomic and somatic reflex responses to pain.

Orthopedic and plastic reconstructive surgeries can be of prolonged duration, hence sensory and motor blockade along with profound analgesia are the main requirements for such surgeries. Due to the nature and site of the surgeries, regional anesthesia is the anesthetic technique of choice. Regional anesthesia offers various advantages over general anesthesia such as preservation of consciousness and the protective reflexes. ${ }^{1}$ This is of prime importance particularly in emergency situations, where the patients are with full stomach, not adequately starving, and in patients with poor risk or having high risk for surgery.

It allows better postoperative recovery, provides postoperative analgesia, preserves mental functions, and prevents postoperative sore throat, nausea, and vomiting caused by general anesthesia.

Brachial plexus block is one of the most widely used blocks for upper limb surgeries involving the hand, forearm, elbow, and shoulder. ${ }^{2}$ Local anesthetic drugs are traditionally used to provide anesthesia and analgesia with any regional block technique. Attempts have been made to prolong intraoperative anesthesia and postoperative analgesia, using various methods and additives. The regional block can be made continuous by insertion of a cannula or a catheter through which boluses or continuous infusions of local anesthetic or additive drugs are injected. Over the years, many adjuvant drugs have been tried with local anesthetics, for example, vasoconstrictors like adrenaline, clonidine, neostigmine, opioids, hyaluronidase, and more recently benzodiazepines such as midazolam.

Adjuncts to local anesthetics for brachial plexus block may enhance the quality and duration of analgesia. ${ }^{3}$ Midazolam, a water-soluble benzodiazepine, is known to produce antinociception and enhance the effect of local anesthetics when given via epidural or intrathecal route. 
The aim of our study was to assess the effect of midazolam in terms of sensory and motor blockade and analgesia when added to local anesthetics in brachial plexus block.

\section{MATERIALS AND METHODS}

After taking approval from the institution's ethics committee, written informed, valid consent was taken from all patients after explaining the study protocol. It was a prospective, randomized, double blind study.

A total of 60 patients of either sex, aged 18-60 years, American Society of Anesthesiologists grade I/II, posted for upper limb surgeries under supraclavicular brachial plexus block with the help of peripheral nerve stimulator were included in the study.

American Society of Anesthesiologists grade III, IV, or V, lactating women, and patients with history of hypersensitivity to local anesthetic drugs, uncooperative patients, patients having systemic disorders such as hypertension, diabetes mellitus, seizure disorders, bronchial asthma, patients with deranged hepatic and renal functions, patients having coagulation disorders and any infection at the site of injection, and patients having any peripheral neuropathy were excluded from the study.

Preanesthetic assessment included medical/surgical history, general/systemic examination, airway examination and investigations, such as complete hemogram, bleeding time, and clotting time, chest $\mathrm{x}$-ray, and in addition fasting blood sugar, and electrocardiogram for patients more than 35 years of age.

Peripheral venous cannulation using 20 G/18 G angiocath was done on dorsum of hand. Monitors including blood pressure cuff, cardioscope, pulse oximeter were attached to patient. Baseline hemodynamics like pulse, blood pressure, oxygen saturation, and respiratory rate were noted.

Patients were randomly allocated into two groups each. Group lignocaine-bupivacaine-midazolam (LBM) received $10 \mathrm{ml}$ of $0.5 \%$ bupivacaine with $50 \mu \mathrm{g} / \mathrm{kg}$ of midazolam (preservative free) $+20 \mathrm{ml}$ of $2 \%$ lignocaine with adrenaline $(1: 200,000)$, whereas Group lignocainebupivacaine (LB) received $10 \mathrm{ml}$ of $0.5 \%$ bupivacaine + $20 \mathrm{ml} 2 \%$ lignocaine with adrenaline $(1: 200,000)$ in the brachial plexus block by supraclavicular approach using peripheral nerve stimulator.

Vital parameters like pulse, blood pressure, oxygen saturation, respiratory rate along with sensory and motor blockade, pain scores visual analog scale (VAS) ${ }^{4}$ and sedation scores (Ramsay sedation scores) ${ }^{5}$ were checked every minute for the first 5 minutes, every 5 minutes for the next 15 minutes, and every 10 minutes thereafter, till the end of procedure.
Onset of sensory blockade is defined as time elapsed from injection of drug to complete loss of cold perception of upper limb elicited by using spirit-soaked cotton or pinprick.

Duration of sensory blockade is defined as the duration between injection of drug and return of pinprick sensation.

Onset of motor blockade is defined as time elapsed from injection of drug to complete motor block elicited by asking the patient to adduct the shoulder, flex the forearm, and hand against gravity.

Duration of motor blockade is defined as the duration between drug injection to complete return of motor power with movement of all upper limb joints.

Rescue analgesia was given with inj diclofenac $75 \mathrm{mg}$ intramuscularly if the pain score by VAS was more than 4 .

Adverse effects like hypotension, bradycardia, nausea, vomiting, respiratory depression, and excessive sedation if occurred were noted. The patient was followed up postoperatively till he recovered completely from sensory and motor block and analgesia.

Statistical analyses were performed using SPSS software version 13 published by SPSS, Inc. and released on September 14, 2004. The qualitative variable like gender was presented as frequency and percentage and compared between the two groups using chi-square test. All quantitative variables namely blood pressure, pulse, $\mathrm{O}_{2}$ saturation, age, weight, and duration of surgery were represented in terms of mean and standard deviation and compared using unpaired $t$-test. Comparison was done at $5 \%$ level of significance. Onset and duration of sensory and motor blocks, duration of analgesia were also compared using unpaired $t$-test. A p-value $<0.05$ was considered statistically significant. Scales like sedation and VAS scores were compared between groups using Mann-Whitney test.

\section{RESULTS}

A total of 60 patients were recruited in the two groups of 30 each randomly. Group LBM received $10 \mathrm{ml}$ of $0.5 \%$ bupivacaine with $50 \mu \mathrm{g} / \mathrm{kg}$ of midazolam (preservative free) $+20 \mathrm{ml}$ of $2 \%$ lignocaine with adrenaline $(1: 200,000)$, whereas Group LB received $10 \mathrm{ml}$ of $0.5 \%$ bupivacaine + $20 \mathrm{ml} 2 \%$ lignocaine with adrenaline $(1: 200,000)$ in the brachial plexus block by supraclavicular approach using peripheral nerve stimulator.

No statistically significant difference was found by applying unpaired $t$-test $(p>0.05)$ in the demographic data (Table 1).

The onset of sensory blockade was faster in Group LBM (5.267 minutes) as compared with Group LB (9.4 minutes). Similarly, onset of motor blockade was faster in Group 


\begin{tabular}{llll}
\hline \multicolumn{4}{c}{ Table 1: Demographic profile } \\
\hline Parameter & Group LBM $(n=30)$ & Group LB $(n=30)$ & $p$-value \\
\hline Age (years) & $34.50( \pm 12.437)$ & $31.57( \pm 11.837)$ & 0.353 \\
Sex ratio (M:F) & $21: 9$ & $23: 7$ & \\
Weight (kg) & $57.53( \pm 6.141)$ & $59.2( \pm 5.530)$ & 0.274 \\
Duration of & $2.483( \pm 0.776)$ & $2.408( \pm 0.934)$ & 0.736 \\
surgery (hours) & & & \\
\hline
\end{tabular}

LBM: lignocaine-bupivacaine-midazolam; LB: lignocainebupivacaine

Table 2: Comparison of onset and duration of sensory and motor blockade

\begin{tabular}{lllll}
\hline & Group LBM & & Group LB & \\
\cline { 2 - 2 } & Mean $\pm S D$ & & Mean $\pm S D$ & p-value \\
\hline $\begin{array}{l}\text { Onset of sensory } \\
\text { blockade (min) }\end{array}$ & $5.267 \pm 2.348$ & & $9.4 \pm 3.962$ & $<0.005$ \\
$\begin{array}{l}\text { Duration of sensory } \\
\text { blockade (hours) }\end{array}$ & $5.133 \pm 0.9864$ & $3.117 \pm 0.622$ & $<0.005$ \\
$\begin{array}{l}\text { Onset of motor } \\
\text { blockade (min) }\end{array}$ & $8.533 \pm 3.866$ & $13.47 \pm 4.688$ & $<0.005$ \\
$\begin{array}{l}\text { Duration of motor } \\
\text { blockade (hours) }\end{array}$ & $6.292 \pm 1.075$ & $4.1 \pm 0.712$ & $<0.005$ \\
\hline
\end{tabular}

LBM: lignocaine-bupivacaine-midazolam; LB: lignocainebupivacaine; SD: standard deviation

LBM (8.533 minutes) as compared with Group LB (13.47 minutes). Statistically significant difference was found by applying unpaired $t$-test $(\mathrm{p}<0.05)($ Table 2$)$.

The duration of sensory blockade was prolonged in Group LBM (5.13 hours) as compared with Group LB (3.117 hours). Similarly, the duration of motor blockade was prolonged in Group LBM (6.292 hours) as compared with Group LB (4.1 hours). Statistically significant difference was found by applying unpaired $t$-test $(\mathrm{p}<0.05)$ (Table 2).

The duration of analgesia was prolonged in Group LBM (11.72 hours) as compared with Group LB (6.38

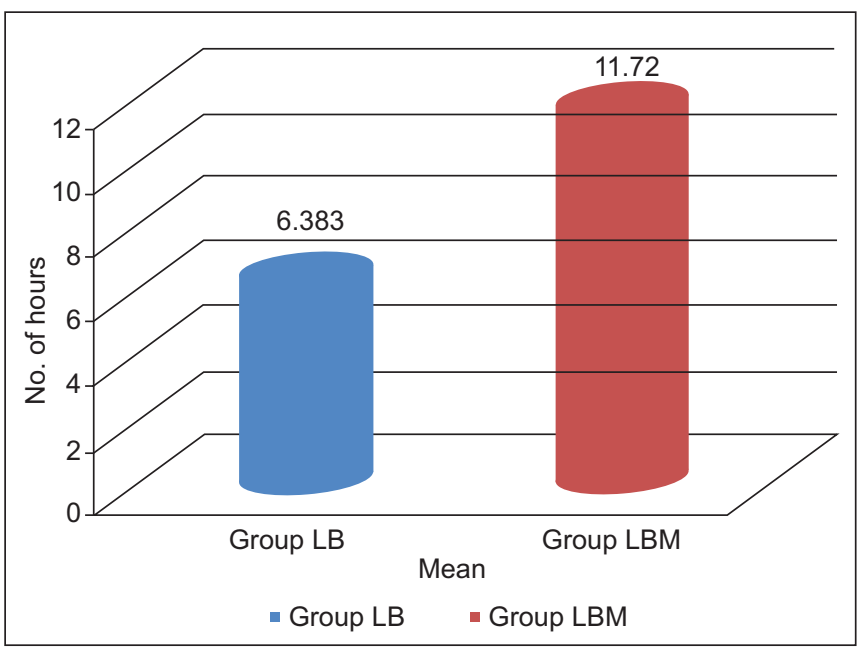

Graph 1: Comparison of duration of analgesia. LBM: lignocainebupivacaine-midazolam; LB: lignocaine-bupivacaine hours). Highly significant difference was found statistically in both the groups (Graph. 1).

Intraoperative changes in pulse rate and blood pressure were noted. Comparison was done by applying unpaired $t$-test. No statistically significant difference was found in pulse rate except at the 4th, 5th, and 8th hour $(\mathrm{p}<0.05)$. Significant difference in systolic blood pressure was found at 10 minutes, 30 minutes, 1 st hour, 2nd hour upto 8th hour (Graph 2). Ramsay sedation score was compared with unpaired $t$-test and found to be higher in group LBM as compared to group LB. Maximum sedation score of 4 was seen in one patient in group LBM (Graph 3).

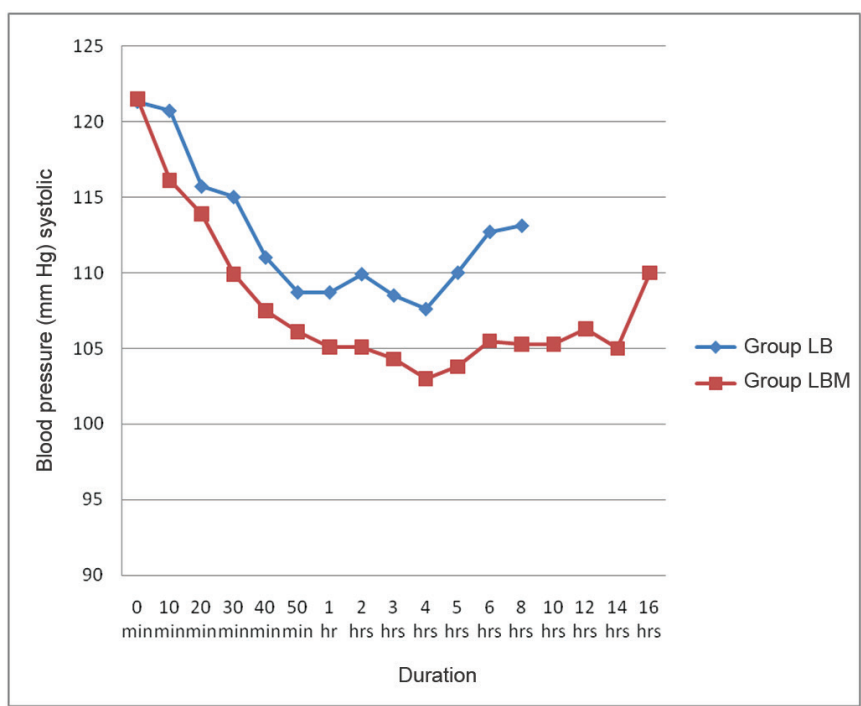

Graph 2: Comparison of changes in intraoperative systolic blood pressure. LBM: lignocaine-bupivacaine-midazolam; LB: lignocaine-bupivacaine

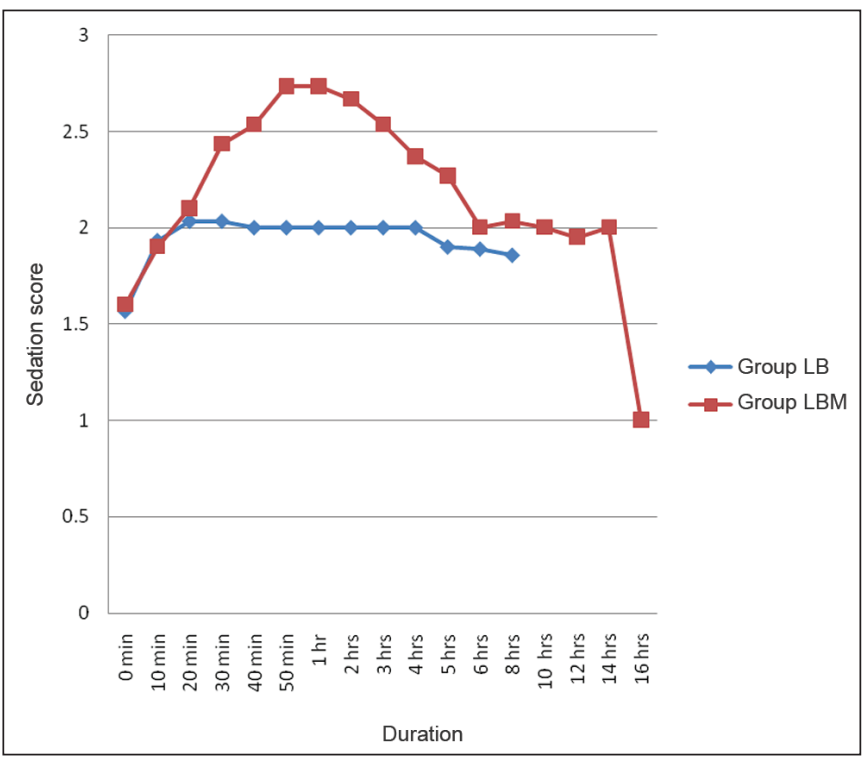

Graph 3: Comparison of changes in Ramsay sedation score. LBM: lignocaine-bupivacaine-midazolam; LB: lignocainebupivacaine 


\section{DISCUSSION}

Postoperative pain relief provides comfort and inhibits trauma-induced nociceptive impulses, thereby blunting autonomic and somatic reflex responses to pain. Peripheral neural blockade is a well-accepted component of comprehensive anesthetic care. Its role has expanded around a vast area not only intraoperatively but also into postoperative and chronic pain management.

Brachial plexus blocks with local anesthetic drugs provide a useful alternative to general anesthesia for upper limb surgery. Any adjuvant in brachial plexus should prolong the analgesic effect of local anesthetic without incurring undue systemic side effects or prolonging the motor blockade.

Various adjuvant drugs have been evaluated in conjunction with local anesthetics such as opioids namely buprenorphine, fentanyl, sufentanil, butorphanol, tramadol, hyaluronidase, dexamathasone, ketamine, and bicarbonate. In many studies, the results have been varied and inconclusive, because of associated side effects or doubtful efficacy. Midazolam, a water-soluble benzodiazepine, is known to produce antinociception and enhance the effect of local anesthetic when given epidurally or intrathecally. Midazolam produces this effect by its action on gamma aminobutyric acid type A (GABA-A) receptors. ${ }^{6,7}$ Gamma aminobutyric acid receptors have also been found in peripheral nerves.

The effect of adding midazolam to a local anesthetic solution in peripheral nerve block has been studied by Jarbo et $\mathrm{al}^{8}$ in 2005 by adding preservative-free midazolam $50 \mu \mathrm{g} / \mathrm{kg}$ to $30 \mathrm{ml}$ of $0.5 \%$ bupivacaine compared with plain $0.5 \%$ bupivacaine. Kim et $\mathrm{al}^{9}$ in 2008 studied the effect of the addition of Fentanyl and midazolam to lignocaine in a supraclavicular brachial plexus block.

We have sought to determine the onset, duration, and analgesic effect of midazolam-bupivacaine with $2 \%$ lignocaine and adrenaline $(1: 200,000)$ combination compared with plain bupivacaine with $2 \%$ lignocaine and adrenaline $(1: 200,000)$ for brachial plexus block. Mixing of these drugs did not show any physical changes like precipitation, turbidity, changes in color, etc.

The age, gender, weight, and duration of surgery were comparable in both the groups. The onset of sensory block and motor block was significantly faster in LBM group as compared with LB group. The hastened onset of both sensory and motor blockade could be due to a local anesthetic property of midazolam and its synergistic action with that of local anesthetics. ${ }^{10}$

In our study, duration of motor blockade and sensory blockade was prolonged compared to control group. Maximum number of patients in group LBM had duration of sensory blockade between 4 and 5 hours, whereas in group LB it was between 2 and 5 hours. Similarly, duration of motor blockade ranged from 6 to 7 hours in group LBM, whereas in group LB it was between 3 and 4 hours.

Some studies supported our findings, ${ }^{9}$ whereas some authors did not find any difference in duration of sensory and motor block between the two groups. ${ }^{8}$

Various studies with midazolam in central neuraxial blockade have been done and it was proven that midazolam with bupivacaine improves analgesia characteristics compared to bupivacaine alone. ${ }^{11-13}$

The study group has shown improved analgesia, as manifested by lower pain scores and prolonged duration of analgesia of nearly 10 to 12 hours with an average of 11.7 hours, thereby decreasing the need for systemic analgesics. Similar results were found in earlier studies.

Hemodynamic parameters such as pulse rate and oxygen saturation were comparable in both the groups. However, in group LBM, slightly lower pulse rates were seen. Statistically significant difference in systolic blood pressure was noted in group LBM as compared with group LB for most intraoperative and postoperative periods, mainly at 10 minutes, 30 minutes, 1 st hour, 2 nd hour and extending upto 8 th hour $(\mathrm{p}<0.05)$. These changes in pulse rate and systolic blood pressure may be due to the systemic effect of midazolam. ${ }^{14}$ No change in oxygen saturation was found in either of the groups, suggesting that patients did not experience any desaturation due to the respiratory depressive effect of midazolam.

Visual analog scale scores were found to be significantly lower in patients who received midazolam with bupivacaine. Requirement for rescue analgesic was earlier in group LB ( $\sim 8$ hours) than in group LBM ( 14 hours). Also the pain scores increased gradually in the study group as compared with relatively rapid increase in the control group. This difference in pain scores was found to be statistically significant, especially from 50 minutes onward $(p<0.05)$. The prolonged analgesia in the study group is due to the action of midazolam on GABA-A receptors present in the brachial plexus and thus producing antinociception. ${ }^{11,13}$

We studied midazolam at a dose of $50 \mu \mathrm{g} / \mathrm{kg}$, as this dose has been used in previous studies in central neuraxial block with no significant adverse side effects. ${ }^{8}$

In our study, sedation scores were higher in the study group, that is, group LBM compared with group LB postoperatively. This may have been due to partial vascular uptake of the drug (midazolam), and its transport to the central nervous system where it acts and produces sedation. ${ }^{15}$ Though the mean sedation scores were higher in group LBM as compared with group LB, 
we did not observe any clinically significant sedation in the study group except in one patient where the sedation score was 4 . No patient experienced airway compromise or required airway assistance.

A similar study has proved that bupivacaine (0.5\%) in combination with midazolam $(50 \mu \mathrm{g} / \mathrm{kg})$ quickened the onset as well as prolonged the duration of sensory and motor blockade of the brachial plexus. It also improved postoperative analgesia without producing any adverse effects. ${ }^{16}$

\section{CONCLUSION}

Midazolam $50 \mu \mathrm{g} / \mathrm{kg}$ (preservative free) when added to $10 \mathrm{ml}$ of $0.5 \%$ bupivacaine $+20 \mathrm{ml}$ of $2 \%$ lignocaine with adrenaline $(1: 200,000)$ for supraclavicular brachial plexus block hastens the onset of sensory and motor blockade, the combination produced improved analgesia, as manifested by lower pain scores and prolonged duration of analgesia.

\section{REFERENCES}

1. Liu SS, Strodtbeck WM, Richman JM, Wu CL. A comparison of regional versus general anesthesia for ambulatory anesthesia: a meta-analysis of randomized controlled trials. Anesth Analg 2005 Dec;101(6):1634-1642.

2. Tran QH, Clemente A, Doan J, Finlayson RJ. Brachial plexus blocks: a review of approaches and techniques. Can J Anesth 2007 Aug;54(8):662-674.

3. Murphy DB, McCartney CJ, Chan VWS. Novel analgesic adjuncts for brachial plexus block: a systematic review. Anesth Analg 2000 May;90(5):1122-1128.

4. Bodian CA, Freedman G, Hossain S, Eisenkraft JB, Beilin Y. Visual analogue scale for pain: clinical significance in postoperative patients. Anesthesiology 2001 Dec;95(6):1356-1361.

5. Ramsay MA, Savege TM, Simpson BR, Goodwin R. Controlled sedation with alphaxolone-alphadalone. Br Med J 1974 Jun22;2 (5920):656-659.
6. Ghai B, Makkar JK, Chari P, Rao KL. Addition of midazolam to continuous postoperative epidural bupivacaine infusion reduces requirement for rescue analgesia in children undergoing upper abdominal and flank surgery. J Clin Anesth 2009 Mar;21(2):113-119.

7. Goodchild CS, Noble J. The effect of intrathecal midazolam on sympathetic nervous system reflexes in man-a pilot study. Br J Clin Pharmacol 1987 Mar;23(3):279-285.

8. Jarbo K, Batra YK, Panda NB. Brachial plexus block with midazolam and bupivacaine improves analgesia. Can J Anaesth 2005 Oct;52(8):822-826.

9. Kim MS, Hwang BS, Hwang BM, Kang SS, Son HJ, Cheong IY, Lee HJ. Effect of the addition of fentanyl and midazolam to lignocaine in supraclavicular block. Korean J Anaesthesiol 2008 Feb;54(2):167-172.

10. Kim MH, Lee YM. Intrathecal midazolam increases the analgesic effect of spinal blockade with bupivacaine in patients undergoing haemorrhoidectomy. Br J Anaesth 2001 Jan;86(1):77-79.

11. Gulec S, Buyukkidan B, Oral N, Ozcan N, Tanreverdi B. Comparison of caudal bupivacaine, bupivacaine-morphine and bupivacaine-midazolam mixtures for postoperative analgesia in children. Eur J Anaesthesiol 1998 Mar;15(2): 161-165.

12. Sen A, Rudra A, Sarkar SK, Biswas B. Intrathecal midazolam for postoperative pain relief in caesarean section delivery. Indian J Med Assoc 2001 Dec;99(12):683-686.

13. Nishiyama T, Matsukawa T, Hanaoka K. Acute phase histopathological study of spinally administered midazolam in cats. Anesth Analg 1999 Sep;89(3):717-720.

14. Reeves JG, Fragen RJ, Vinik HR, Greenblatt DJ. Midazolam: pharmacology and uses. Anesthesiology 1985 Mar;62(3): 310-324.

15. Tucker AP, Lai C, Nadeson R, Goodchild CS. Intrathecal midazolam I: a cohort study investigating safety. Anesth Analg 2004 Jun;98(6):1512-1520.

16. Laiq N, Khan MN, Arif M, Khan S. Midazolam with bupivacaine for improving analgesia quality in brachial plexus block for upper limb surgeries. J Coll Physicians Surg Pak 2008 Nov;18(11):674-678. 